\title{
Highlighting the Journey So Far with Cancer and Chemotherapy
}

\author{
Kafayat Aderonke Yusuf and Kyoungtae Kim* \\ Department of Biology, Missouri State University, Springfield, Missouri, United States \\ of America \\ *Corresponding Author: Kyoungtae Kim, Department of Biology, Missouri State \\ University, Springfield, Missouri, United States of America.
}

Received: April 17, 2020

Published: May 22, 2020

(C) All rights are reserved by Kafayat

Aderonke Yusuf and Kyoungtae Kim.

\begin{abstract}
Cancer is one of the most deadly diseases in the world with thousands of deaths occurring globally from the disease. Despite several interventions, chemotherapy has proven to be one of the most effective treatment patterns used for majority of cancer types. This review is aimed at emphasizing the current updates with cancer chemotherapy suggesting the potentials for a new set of chemotherapy agents in cancer treatment.

Keywords: Cancer; Chemotherapy; Disease; Treatment
\end{abstract}

\section{Introduction}

Cancer can be described as a disease that involves a group of abnormal cells growing out of control, disregarding the normal patterns of cell division [1]. Ideally, normal dividing cells are constantly regulated by cues that dictate whether the cells should divide, differentiate into another cell, or undergo apoptosis [1]. Overtime, cancer cells become resistant to these signals, becoming autonomous to cell growth and division prompts, and consequently leading to uncontrolled cell division, growth and proliferation $[1,2]$. Over 10 million new cases of cancer are reported each year, and cancer-related deaths are projected to increase in the near future with an estimation by the World Health Organization of approximately 13 million cancer-related deaths by the year 2030 [2]. Generally, cancer cells are believed to develop from normal cells due to damage of DNA. Typically, when DNA becomes damaged, the body is able to repair it. Unfortunately, in cancer cells, damaged DNA isn't repaired and occasionally can be inherited [3].

\section{History and causes of cancer}

Cancer has been recognized for several hundred years, with its earliest description in a book titled "Cautions against the immoderate snuff" written by physician John Hill [4]. The book was published in 1761 as a result of scientific findings which observed that tobacco snuff caused "polypus" which was described as a small vascular growth on the epithelium of a mucous membrane [4]. No significant studies had been made till over two decades later when Hill's findings paved the way for new studies on cancer epidemiology where it was noted that tobacco smoking caused lung cancer
[4]. The first occupational link to cancer was reportedly established in 1775 when Sir Percivall Pott of Saint Bartholomew's Hospital in London wrote an essay that linked soot leads to high incidence of scrotal cancer in young men that worked as chimney sweeps which he then referred to them as the chimney-sweepers' cancer [5]. No significant studies on carcinogens cancer causing agents, were published till the early $20^{\text {th }}$ century when two Japanese investigators developed the first animal assay for carcinogens. They repeatedly applied coal tar on the skin of rabbit ears, which resulted in the development of tumors after a few weeks. Subsequently, the rats and mice were found to be more responsive to the carcinogen [4]. Over the years, many compounds and mixtures have been recognized as potential human carcinogens. Numerous findings have illustrated that asbestos, chromium, nickel and arsenic compounds, vinyl chloride, aflatoxins and most notably tobacco smoke are potential carcinogens [6]. It has also been reported that there is a high rate of cancer occurrence in patients with viral infections from Hepatitis $B$ and $C$ virus, human papillomavirus (HPV), as well as human immunodeficiency virus (HIV) that have contributed to cases of liver cancer, lymphomas, carcinomas, and nasopharyngeal cancers $[1,3]$. Prolonged sun exposure is a factor causing skin damage, due to increased exposure to ultraviolet rays from the sun; the fast rise in tanning salons have also fostered the increased rate of skin cancers (melanomas) [7].

\section{Cancer treatment and prevention}

Findings have suggested that the risk of getting cancer can be minimized by lifestyle changes and modifications [1,8]. Primary 
cancer prevention strategies encouraged includes quitting smoking and minimizing alcohol consumption [8]. Likewise, diet modification through the incorporation of fruits and vegetables as well as a high fiber diet can help reduce the incidence of stomach and colon cancer [1,9]. Currently used treatment for cancer includes surgery, radiation, chemotherapy and sometimes hormonal blocking [10]. Surgery becomes an ineffective process in cancer treatment when the tumor has spread to different parts of the body. Radiation therapy, although effective, is also limiting because healthy cells are harmed in the process, and therefore, newer radiation machines that concentrate the energy to only cancerous cells are being considered currently in use $[5,11]$. Chemotherapy involves the use of anticancer medications. In particular, this therapy is often prescribed when cancerous cells have spread widely in the body, but most times a combination of such medications works better than a single medication [5]. Cancer chemotherapy has also been reported to achieve partial or complete response where either half or all of detectable cancerous cells are eliminated. The set back of chemotherapy use is the development of drug resistance by cancerous cells over time [12].

\section{Cancer chemotherapy}

A famous German Chemist Paul Ehrlich coined the word "chemotherapy" and defined it as the use of chemicals to treat disease [5]. Chemotherapy works by killing rapidly dividing cells, halting their growth and spread or slowing down their development. Chemotherapy can, however, affect healthy cells, leading to unwanted side effects [13]. The use of various metal based compounds in treatment of several diseases is dated to ancient times due to their therapeutic properties [14]. Metals are part of numerous biological activities, such as reaction catalysts, and structural functions to the exchange of electrons in cells. They are often situated in the enzyme catalytic domains and are profoundly employed in cellular activities. These metals are often needed in just trace amount to facilitate catalytic events in the cell [15]. In spite of the prevalence of metal-based compounds in the treatment of diseases since ancient times, lack of appropriate dosage was a major drawback associated with its use. Medical experts at that time had little or no knowledge about dose-related biological response, but the emergence of cell biology, molecular biology, and biochemistry paved way for the design of metal based compounds to target specific molecules in the cell [16].

The advent of platinum based compound cisplatin in 1960 by Barnett Rosenberg [17], was a major advancement in the use of metal based compounds in the treatment of cancer cells. This major breakthrough was considered the foundation for develop- ment of modern day metal based anticancer drugs [17]. Distinctive features of metals such as reactivity towards organic substrate, variable coordination modes, and redox activity have enhanced their use in cancer therapy [14]. These unique characteristics were the attractive site of metals in the model of Metal complexes that binds to the biomolecular target with a resultant disruption in the mechanism of cell proliferation ultimately leading to death of the cells. The recent groups of metal based synthesized compounds are designed to achieve higher levels of cytotoxicity and lesser side effects that could not be achieved with the compounds already in use [18]. Generally, platinum compounds, particularly cisplatin, are the most prevalent of the metal based compounds used in cancer chemotherapy [19]. Platinum complexes act as an adjuvant in cancer treatment to facilitate apoptosis or programmed cell death [13]. These metal complexes are mostly recommended for the treatment of ovarian, testicular, breast, ovarian, prostate and lung cancers [20].

For over three decades now, platinum based anticancer drugs, including cisplatin and its analogues, have dominated the treatment of cancers by chemical events [19,21]. The discovery of cisplatin (cis-diaminedichloro-platinum(II)) decades ago marked the beginning of a tremendous development in the production of platinum based anticancer drugs [13]. Cisplatin is a very efficient anticancer drug, with several positive results against testicular, ovarian, bladder tumors, as well as head and neck malignancies [22]. Research has indicated that cisplatin is usually administered intravenously rather than orally because of its low solubility in water $[17,22]$. The mechanism of cisplatin action is by passive diffusion [23] and the cytotoxicity of cisplatin is believed to arise from its binding to DNA and the formation of covalent cross-links [23]. Binding of cisplatin to DNA then causes alteration of helical structure and results in halting of DNA replication and transcription [24]. The disrupted DNA structure can be used as a recognition or binding site for cellular proteins such as repair enzymes, transcription factors, histones and high-mobility group (HMG) proteins [25]. The process of binding of the HMG proteins to cisplatinDNA lesions has been suggested to facilitate the antitumor activity of the drugs [26]. The anticancer property of cisplatin is also influenced by the efficiency of cisplatin-DNA adduct removal by the cellular repair machinery, with nucleotide excision repair being a major pathway [23,27]. Another commonly used platinum based drug is, carboplatin (diamine[1,1-cyclobutanedicarboxylato(2-)]$0,0^{\prime}$-platinum (II)) [28]. The basic pharmacokinetic differences between cisplatin and carboplatin depend primarily on the slower rate of conversion of the latter to reactive species. Regarding the interaction of carboplatin with DNA, results from studies provide 
evidence that the reaction is initiated via ring-opening in carboplatin and subsequent binding with DNA constituents. The side effects of using carboplatin is also described as minimal when compared with cisplatin, and the drug is said to be better tolerated by the body and can be used at higher prescription doses than cisplatin [29]. Oxaliplatin is another platinum based anticancer drug that has been approved for use against cancer cells that do not respond to cisplatin. Its mechanism of action is not completely understood, but it is believed to interact with DNA in a similar way to cisplatin and carboplatin. Oxaliplatin can be employed for the use with other medications against the treatment of advanced colorectal cancer [29].

Platinum and palladium are believed to have similar physical and chemical properties. The significant similarity between the coordination chemistry of palladium (II) and platinum (II) compounds has triggered the studies of Pd (II) complexes as antitumor drugs [29]. Likewise, hydrolysis of palladium is about $10^{5}$ times faster than its platinum counterpart, which enables it to dissociate instantly in solution and ultimately is unable to reach its pharmacological targets [21]. Research has indicated that one of the methods to improve the biological activity of Pd (II) complexes is its combination with selected ligands that will significantly decrease the rate of hydrolysis at the metal site [30]. Several studies have focused on the preparation of Pd (II) complexes bearing bidentate ligands as a way to stabilize these compounds and to prevent any possible cis-trans isomerism [31].

\section{Reactive oxygen species and chemotherapy}

Reactive oxygen species (ROS) has been described as unstable, reactive, partially reduced oxygen derivatives that are generated as an end product of metabolism. They include hydrogen peroxide $\left(\mathrm{H}_{2} \mathrm{O}_{2}\right)$, superoxide anion $\left(\mathrm{O}_{2}^{-}\right)$, singlet oxygen $\left({ }^{1} \mathrm{O}_{2}\right)$, hydroxyl radical $(\cdot \mathrm{OH})$ and sometimes peroxynitrites ( $\left.\mathrm{ONOO}^{-}\right)$[32], that acts as a borderline between reactive oxygen and reactive nitrogen species. They are believed to act as secondary messengers in cell signaling and are essential for various biological processes in healthy and diseased cells [32]. Altering of ROS levels is a mechanism shared by most chemotherapeutics due to their effect in promoting programmed cell death [33]. In cancer cells, ROS levels are increased due to both environmental and internal mechanisms. The overall balance of ROS and the combined positive and negative effects of ROS all contribute to the final impact on cancer biology [34]. Most chemotherapeutics generate ROS in cancer cells, and findings from several studies indicate that chemotherapeutic amplification of ROS levels pushes the already increased cancer cells over a threshold to cause cell death and is one of the proposed mechanisms by which multiple chemotherapies foster tumor regression $[34,35]$. Anthracyclines, such as doxorubicin, daunorubicin and epirubicin, are believed to produce the highest levels of cellular ROS [36]. Platinum coordination complexes, alkylating agents and camptothecins are said to also generate high levels of ROS [37].

Studies further revealed that two major reasons are attributed to increased ROS levels in chemotherapy; elevation of mitochondria ROS generation and suppression of the cellular antioxidant system [32,38]. Antibiotics based chemotherapeutic agents such as anthracyclines, doxorubicin, bleomycin, and platinum coordination complexes, also target the mitochondria and induce cellular ROS generation [38]. Studies also indicate that reactive oxygen and nitrogen species play key roles in cancer initiation and survival, by modifying tumor growth through numerous cellular and molecular events such as DNA damage and genome instability [39]. Nitric oxide (NO) is a bioactive molecule generated by NO synthases (NOSs) in mammalian cells. By interacting with numerous diverse biomolecules, NO and its derivatives are engaged in a broad range of cellular responses, from neurotransmission to regulation of vascular tone to immune responses and tumorigenesis [40]. In majority of cancers, NOS activity has been implicated with increased tumor growth, malignant transformation, angiogenesis and most notably resistance to apoptosis [41]. Research pointed out that there is a strong correlation between the prevalence of tumor cells generating inducible NOS (iNOS; i.e. NOS2) and shortened survival of patients with advanced skin cancer [42]. Inhibition of NO production by cisplatin in vitro was indicated to act synergistically with reduction in tumor development and increased sensitivity to cisplatin [43]. Several pathways are believed to be activated after treatment with chemotherapeutics; The PI3K/AKT pathway is believed to be frequently mutated in human cancers [44]. Chemotherapeutic agents like cisplatin are believed to trigger cancer cell apoptosis and autophagy through dose-dependent stimulation of ROS-MAPK signaling [45].

\section{Recent findings}

A currently studied group of ligands called cyanoximes, is the common name for a family of compounds with the general formula $\mathrm{NC}-(\mathrm{C}=\mathrm{N}-\mathrm{OH})-\mathrm{R}$, where $\mathrm{R}$ is an electron-withdrawing group [46]. Cyanoximes have been described as outstanding ligands with unique biological properties such as growth regulation, antimicrobial and detoxification activities [46,47]. In line with the idea of further exploration of new, non-traditional platinum complexes, cytotoxic bivalent Pd and Pt complexes with deprotonated MCO and PiPCO ligands were shown to possess in vitro activity comparable to cisplatin [47]. These square-planar Pd and Pt complexes 
represent the first group of active, novel oxime-based bis-chelates. However, prior to the above studies, no high-yield preparations of Pd, Pt-cyanoximates were developed, no direct structural information about these complexes was available, and their electronic structure was not fully understood [30]. Studies have revealed that cyanoximes are excellent ligands for a strong binding of a variety of metal ions in formed complexes, and they are considered much better ligands than traditional aldoximes and ketoximes [48]. The anti-proliferative activity and cytotoxicity of cyanoximes and their metal complexes have not been properly studied. The first bivalent palladium and platinum cyanoximate was synthesized, characterized and described by several authors [49]. This paper studied the in vitro effect of two MCO- based complexes of Pd and Pt on the anti-proliferating activity of human cervical cancer HeLa cell lines with cisplatin as a positive control. The study stated that $\mathrm{Pd}(\mathrm{MCO})_{2}$ caused $28 \%$ death, and its platinum analogue $\mathrm{Pt}(\mathrm{MCO})_{2}$, yielded $16 \%$ death [49]. A follow up studies highlighted the in vitro biological activity of bivalent Pd and Pt cyanoxime complexes with ligand derivatives of substituted cyan-acetamides abbreviated as HPiPCO and HMCO [30]. In this study, $\mathrm{Pd}(\mathrm{MCO})_{2}$ and $\mathrm{Pt}(\mathrm{MCO})_{2}$ were tested at varying concentrations against both HeLa (cervical cancer) and WiDr (colon cancer) cell lines. The cytotoxicity study found that $\mathrm{Pt}(\mathrm{MCO})_{2}$ and $\mathrm{Pd}(\mathrm{MCO})_{2}$ affected HeLa cells greatly at $1.0 \mathrm{mM}$ concentrations showing a $42 \pm 3 \%$ and $45 \pm 3 \%$ cell death, respectively. The findings were comparable to values obtained with cisplatin, at $1.0 \mathrm{mM}$, which was used as a positive control, showing a $56 \pm$ $5 \%$ cell death against HeLa cells. Both Pt(MCO) $)_{2}$ and Pd(MCO) $)_{2}$ affected the wellbeing of WiDr cells, causing $73 \pm 9 \%$ and $81 \pm 11 \%$ cell death respectively at $1.0 \mathrm{mM}$. At the same concentration, cisplatin caused a $64 \pm 1 \%$ of cell death under the same conditions [30]. A recent findings in Dr. Gerasimchuk's lab emphasized the synthesis of a new group of cyanoximates; platinum and palladium DECO, (DECO:2-cyano-2-oxiamino- $\mathrm{N}, \mathrm{N}^{\prime}$-diethylaminoacetamide), Bis (2-cyano-2-oxiamino- $\mathrm{N}, \mathrm{N}^{\prime}$-diethylaminoacetamide) platinum $\left(\mathrm{Pt}(\mathrm{DECO})_{2}\right)$ and Bis (2-cyano-2-oxiamino- $\mathrm{N}, \mathrm{N}^{\prime}$-diethylaminoacetamide) palladium ( $\mathrm{Pd}(\mathrm{DECO})_{2}$ ) [50]. Owing to previous and ongoing studies, the newly synthesized cyanoximates reveals possible potentials for a new anti-cancer agent in chemotherapy.

\section{Conclusion}

The discovery of cancer has warranted research into different treatment regimes. With chemotherapy being one of the most widely used, it is relevant to provide updated information about the current state of research about chemotherapeutic agents.

\section{Bibliography}

1. Hejmadi M. "Introduction to Cancer Biology, $2^{\text {nd }}$ edition". Editionn (Denmark: Ventus Publishing) (2013).
2. Ferlay J., et al. "Cancer incidence and mortality worldwide: sources, methods and major patterns in GLOBOCAN 2012". International Journal of Cancer 136 (2015): E359-386.

3. Sudhakar A. "History of Cancer, Ancient and Modern Treatment Methods". Journal of Cancer Science and Clinical Therapeutics 1 (2009): 1-4.

4. Basu AK. "DNA Damage, Mutagenesis and Cancer". International Journal of Molecular Sciences (2018): 19.

5. Vincent T., et al. "A History of Cancer Chemotherapy". Cancer Research 68 (2008): 8643-8653.

6. Hayes RB. "The carcinogenicity of metals in humans". Cancer Causes Control 8 (1997): 371-385.

7. Soehnge H., et al. "Mechanisms of induction of skin cancer by UV radiation". Frontiers in Bioscience 2 (1997): d538-551.

8. Stein CJ and Colditz GA. "Modifiable risk factors for cancer". British Journal of Cancer 90 (2004): 299-303.

9. Anand P., et al. "Cancer is a preventable disease that requires major lifestyle changes". Pharmaceutical Research 25 (2008): 2097-2116.

10. Senapati S., et al. "Controlled drug delivery vehicles for cancer treatment and their performance". Signal Transduction and Targeted Therapy 3 (2018): 7.

11. Chandarana H., et al. "Emerging Role of MRI in Radiation Therapy”. Journal of Magnetic Resonance Imaging 48.6 (2018) 1-11.

12. Housman G., et al. "Drug resistance in cancer: an overview". Cancers (Basel) 6 (2014): 1769-1792.

13. Florea AM and Busselberg D. "Cisplatin as an anti-tumor drug cellular mechanisms of activity, drug resistance and induced side effects". Cancers (Basel) 3 (2011): 1351-1371.

14. Frezza M., et al. "Novel metals and metal complexes as platforms for cancer therapy". Current Pharmaceutical Design 16 (2010): 1813-1825.

15. Bruijnincx PC and Sadler PJ. "New trends for metal complexes with anticancer activity". Current Opinion in Chemical Biology 12 (2008): 197-206

16. Ji HF., et al. "Natural products and drug discovery. Can thousands of years of ancient medical knowledge lead us to new and powerful drug combinations in the fight against cancer and dementia?" EMBO Reports 10 (2009): 194-200. 
17. Pranczk J., et al. "Platinum(II) and Palladium(II) Complex Compounds as Anti-cancer Drugs. Methods of Cytotoxicity Determination". Current Pharmaceutical Analysis 10 (2014): 2-9.

18. Ndagi U., et al. "Metal complexes in cancer therapy - an update from drug design perspective". Drug Design, Development and Therapy 11 (2017): 599-616.

19. Dasari S and Tchounwou PB. "Cisplatin in cancer therapy: molecular mechanisms of action". European Journal of Pharmacology 740 (2014): 364-378.

20. Basu A and Krishnamurthy S. "Cellular responses to Cisplatininduced DNA damage". Journal of Nucleic Acids (2010).

21. Abu-Surrah AS., et al. "Palladium-based chemotherapeutic agents: Routes toward complexes with good antitumor activity". Cancer Therapy 6 (2008): 1-10.

22. Ho GY., et al. "Cisplatin versus carboplatin: comparative review of therapeutic management in solid malignancies". Critical Reviews in Oncology/Hematology 102 (2016): 37-46.

23. Jamieson ER and Lippard SJ. "Structure, Recognition, and Processing of Cisplatin-DNA Adducts". Chemical Reviews 99 (1999): 2467-2498.

24. Lee KB., et al. "Transcription-coupled and DNA damage-dependent ubiquitination of RNA polymerase II In vitro". Proceedings of the National Academy of Sciences of the United States of America 99 (2002): 4239-4244.

25. Kartalou M and Essigmann JM. "Recognition of cisplatin adducts by cellular proteins". Mutation Research 478 (2001): $1-21$.

26. Kane SA and Lippard SJ. "Photoreactivity of platinum(II) in cisplatin-modified DNA affords specific cross-links to HMG domain proteins". Biochemistry 35 (1996): 2180-2188.

27. Yimit A., et al. "Differential damage and repair of DNA-adducts induced by anti-cancer drug cisplatin across mouse organs". Nature Communications 10 (2019): 309.

28. Sakurai H., et al. "Antidiabetic vanadium(IV) and zinc(II) complexes". Coordination Chemistry Reviews 226 (2002): 187-198.

29. Kapdi AR and Fairlamb IJ. "Anti-cancer palladium complexes: a focus on PdX2L2, palladacycles and related complexes". Chemical Society Reviews 43 (2014): 4751-4777.

30. Ratcliff J., et al. "Part 1: Experimental and theoretical studies of 2-cyano-2-isonitroso-N-piperidynylacetamide (HPiPCO), 2-cyano-2-isonitroso-N-morphylacetamide (HMCO) and their Pt- and Pd- complexes". Inorganica Chimica Acta 385 (2012b): $1-11$.

31. Mansuri-Torshizi H., et al. "Synthesis, spectroscopic, cytotoxic, and DNA binding studies of binuclear 2,2'-bipyridine-platinum(II) and -palladium(II) complexes of meso-alpha,alpha'-diaminoadipic and meso-alpha,alpha'diaminosuberic acids". Journal of Inorganic Biochemistry 45 (1992): 135-148

32. Chio IIC and Tuveson DA. "ROS in Cancer: The Burning Question”. Trends in Molecular Medicine 23 (2017): 411-429.

33. Conklin KA. "Chemotherapy-associated oxidative stress: impact on chemotherapeutic effectiveness". Integrative Cancer Therapies 3 (2004): 294-300.

34. Yang H., et al. "The role of cellular reactive oxygen species in cancer chemotherapy". Journal of Experimental and Clinical Cancer Research 37 (2018): 266.

35. Pelicano H., et al. "ROS stress in cancer cells and therapeutic implications". Drug Resistance Updates 7 (2004): 97-110.

36. Li XX., et al. "Emodin as an effective agent in targeting cancer stem-like side population cells of gallbladder carcinoma". Stem Cells and Development 22 (2013): 554-566.

37. Wang H., et al. "Mechanisms of verapamil-enhanced chemosensitivity of gallbladder cancer cells to platinum drugs: glutathione reduction and MRP1 downregulation". Oncology Reports 29 (2013): 676-684.

38. Marullo R., et al. "Cisplatin induces a mitochondrial-ROS response that contributes to cytotoxicity depending on mitochondrial redox status and bioenergetic functions". PLoS One 8 (2013): e81162.

39. Moldogazieva NT., et al. "Reactive Oxygen and Nitrogen Species-Induced Protein Modifications: Implication in Carcinogenesis and Anticancer Therapy". Cancer Research 78 (2018): 6040-6047.

40. Xie $\mathrm{K}$ and Huang S. "Contribution of nitric oxide-mediated apoptosis to cancer metastasis inefficiency". Free Radical Biology and Medicine 34 (2003): 969-986.

41. Fukumura D., et al. "The role of nitric oxide in tumour progression". Nature Reviews Cancer 6 (2006): 521-534. 
42. Lechner M., et al. "Inducible nitric oxide synthase (iNOS) in tumor biology: the two sides of the same coin". Seminars in Cancer Biology 15 (2005): 277-289.

43. Godoy LC., et al. "Endogenously produced nitric oxide mitigates sensitivity of melanoma cells to cisplatin". Proceedings of the National Academy of Sciences of the United States of America 109 (2012): 20373-20378.

44. Mayer IA and Arteaga CL. "The PI3K/AKT Pathway as a Target for Cancer Treatment". Annual Review of Medicine 67 (2016):

11-28.

45. Tang CH and Grimm EA. "Depletion of endogenous nitric oxide enhances cisplatin-induced apoptosis in a p53-dependent manner in melanoma cell lines". The Journal of Biological Chemistry 279 (2004): 288-298.

46. Gerasimchuk N., et al. "Synthesis and characterization of disubstituted arylcyanoximes and their several metal complexes". Inorganica Chimica Acta 361 (2008): 1983-2001.

47. Ratcliff J., et al. "Part 2: In vitro cytotoxicity studies of two ML2 complexes ( $\mathrm{M}=\mathrm{Pd}$, $\mathrm{Pt}$; $\mathrm{L}=2$-cyano-2-isonitroso-N-morpholylacetamide, HMCO) ". Inorganica Chimica Acta 385 (2012a): 11-20.

48. Marcano DC., et al. "The 2-Pyridylcyanoxime and its Complexes". Current Inorganic Chemistry 5 (2015): 98-113.

49. Eddings D., et al. "First bivalent palladium and platinum cyanoximates: synthesis, characterization, and biological activity". Inorganic Chemistry 43 (2004): 3894-3909.

50. Klaus DR., et al. "1D Polymeric Platinum Cyanoximate: A Strategy toward Luminescence in the Near-Infrared Region beyond 1000 nm". Inorganic Chemistry 54 (2015): 1890-1900.

\section{Assets from publication with us}

- Prompt Acknowledgement after receiving the article

- Thorough Double blinded peer review

- Rapid Publication

- Issue of Publication Certificate

- High visibility of your Published work

Website: https://www.actascientific.com/

Submit Article: https://www.actascientific.com/submission.php

Email us: editor@actascientific.com

Contact us: +919182824667

Citation: Kafayat Aderonke Yusuf and Kyoungtae Kim. "Highlighting the Journey So Far with Cancer and Chemotherapy". Acta Scientific Microbiology 3.6 (2020): 118-123. 